
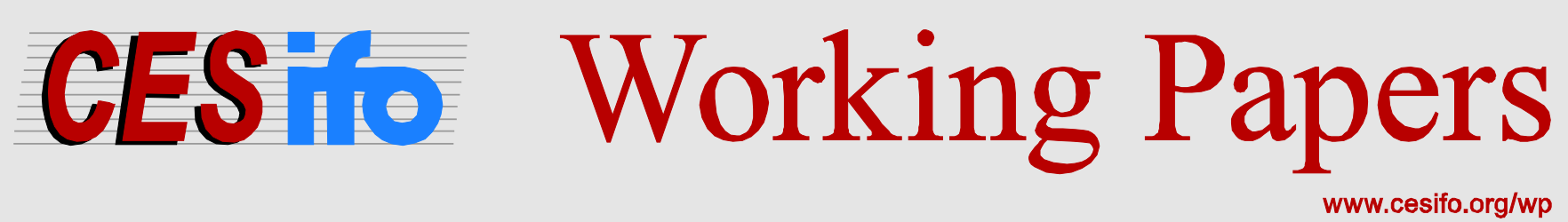

\title{
Working Time Regulation, Unequal Lifetimes and Fairness
}

\author{
Marie-Louise Leroux \\ Gregory Ponthiere
}

\section{CESIFO WORKING PAPER NO. 6271 \\ CATEGORY 1: PUBLIC FinANCE \\ DECEMBER 2016}
An electronic version of the paper may be downloaded
- from the SSRN website:
- from the RePEc website:
- from the CESifo website: wWw.SSRN.com
www.RePEc.org
www.CESifo-group.org/wp




\title{
Working Time Regulation, Unequal Lifetimes and Fairness
}

\begin{abstract}
We examine the redistributive impact of working time regulations in an economy with unequal lifetimes. It is shown that uniform working time reductions, when uncompensated (i.e. constant hourly wage), can reduce inequalities in realized lifetime well-being between short-lived and long-lived persons with respect to the laissez-faire, but at the cost of making the short-lived worse off. When compensated (i.e. constant labour earnings), uniform working time reductions make the short-lived better off, but at the cost of raising inequalities. Then, we characterize the ex post egalitarian optimum, where the realized lifetime well-being of the worst off is maximized, and show that this social optimum involves an increasing age profile in terms of worked hours. We examine the decentralization of that social optimum, and we provide a second-best egalitarian argument for age-dependent working time regulation, which can make the short-lived better off and reduce inequalities in realized lifetime well-being.
\end{abstract}

JEL-Codes: J100, J180, J220.

Keywords: working time regulations, longevity, inequalities, labor supply, premature deaths.

Marie-Louise Leroux

Département des Sciences Economiques

Université du Québec à Montréal

Canada - H3C 3P8 Montréal Québec

leroux.marie-louise@uqam.ca
Gregory Ponthiere

Université Paris Est Créteil (UPEC)

Paris School of Economics

France- 75014 Paris

gregory.ponthiere@ens.fr

December 15, 2016

We would like to thank K. Behrens, V. Barham, L. Larue, J. Martin, F. Moizeau, M. Yazbeck and D. Zwarthoed for their comments and suggestions on this paper. 


\section{Introduction}

Imposing a maximum limit on the number of hours worked everyday is an old idea, which dates back to the first attempts to characterize what an ideal society could be. In his Utopia, Thomas More (1516) described an ideal island where individuals would work 6 hours a day, the rest of time being dedicated to education. In Tommaso Campanella's City of the Sun (1602), each adult would work only 4 hours a day. The main motivation was that goods should serve humans, but that humans should never become instruments of goods.

Since the early 19th century, workers' movements have called for working time reductions. Following those social movements, governments introduced working time regulations specifying a maximum number of hours worked every week. The effects of working time reductions have been studied in details by economists, who estimated their impact on unemployment (Crépon and Kramartz 2002, Chemin and Wasmer 2009), firm productivity (Crépon et al 2004), actual hours worked (Hunt 1999), and female labor supply (Goux et al 2011). ${ }^{1}$

Working time regulations have also significant redistributive effects. When a working time reduction is compensated (i.e. carried out at constant total labor earnings), this implies a rise in the hourly wage, which affects the distribution of income among production factors. ${ }^{2}$ But beyond the impact of working time reductions on the capital/labor partition, little attention has been paid so far to the redistributive effects of working time regulations from a lifecycle perspective.

In a hypothetical world without longevity inequalities, working time regulations would be neutral from a lifecycle perspective, since everyone would go through all stages of life and would face the same constraints imposed by working time regulations. However, under unequal lifetimes, working time regulations are no longer neutral from a lifecycle perspective, since these regulations, by affecting working time and budget constraints in distinct ways across long-lived and short-lived workers, influence the distribution of well-being across them.

The goal of this paper is to examine the redistributive consequences of working time regulations in an economy where individuals have unequal lifetimes. More precisely, we propose to study to what extent working time regulations can be used to reduce inequalities in realized lifetime well-being between long-lived and short-lived persons, and to improve the situation of the unlucky short-lived.

The main motivation for examining the redistributive impact of working time regulations in an economy with unequal lifetime goes as follows. Despite major medical advances, there remain nowadays significant longevity inequalities. From a policy perspective, those inequalities invite some intervention from the government. Indeed, short-lived individuals cannot be regarded as responsible for dying prematurely. ${ }^{3}$ Hence, if one adheres to the Principle of Compensation

\footnotetext{
${ }^{1}$ For a survey of those studies, see Askenazy (2013).

${ }^{2}$ Holmlund and Pencavel (1988) and Friesen, (2000) showed that a reduction in the working time is associated with a significant rise in the hourly wage in countries such as Sweden, the Netherlands and Canada.

${ }^{3}$ Christensen et al (2006) emphasized that about $1 / 4$ to $1 / 3$ of longevity inequalities are due to the genetic background, on which individuals can have no influence.
} 
(Fleurbaey and Maniquet 2004, Fleurbaey 2008), according to which inequalities due to circumstances should be abolished, there is a strong ethical support for public intervention aimed at reducing inequalities due to premature deaths.

At this stage, it is important to underline that compensating a person for a premature death is difficult, because a premature death is a singular damage to be compensated. A major difficulty with the compensation of short-lived persons resides in the fact that ex ante (i.e. before the duration of life is revealed), short-lived persons cannot be identified, whereas, ex post (i.e. after the duration of life is revealed), it is too late to affect the well-being of the short-lived. In that context, it is not easy to see how working time regulations could help compensating short-lived persons.

In order to address that issue, we develop a lifecycle model with risky lifetime, where individuals choose how many hours they work at each age of life, as well as their retirement age. We first characterize the laissez-faire, and examine how uniform working time regulations (either uncompensated or compensated) affect inequalities in lifetime well-being between short-lived and long-lived persons. We also examine the redistributive impact of allowing for overtime work. Then, we contrast the laissez-faire with the ex post egalitarian social optimum (where the realized lifetime well-being of the worst off is maximized). That social optimum was shown to minimize inequalities in realized lifetime wellbeing between short-lived and long-lived persons (see Fleurbaey et al 2014). We then analyze how that social optimum can be decentralized, and the role of age-specific working time regulations in that decentralization.

Anticipating our results, we first show that an uncompensated uniform working time reduction (with or without the possibility of overtime work) reduces, under some conditions, inequalities in realized lifetime well-being between the long-lived and the short-lived, but at the cost of worsening the situation of the short-lived. On the contrary, a compensated working time reduction makes the short-lived better off, but at the cost of increasing inequalities in realized lifetime well-being between the long-lived and the short-lived. Then, we characterize the ex post egalitarian optimum and we show that it involves, in general, a number of worked hours that is increasing with the age. By transferring leisure time and consumption to the young (who include those who will turn out to be short-lived), the ex post egalitarian optimum allows for an equalization of the realized lifetime well-being of short-lived and long-lived persons, despite the non-identification ex ante of the premature dead. We also show that agedependent working time regulation does not allow to fully decentralize the $e x$ post egalitarian optimum, which is achieved by lump sum taxation and by taxing savings returns (so as to induce a decreasing age-profile for consumption). However, age-dependent working time regulations can, under some conditions, both make the short-lived better off and reduce well-being inequalities.

Those analytical findings are complemented by numerical simulations, which show that the ex post egalitarian optimum would involve, at the young age, a strong working time reduction, close to the standards of Campanella's City of the Sun, whereas old-age working time would be significantly increased with respect to current regulations. Focusing on the working time reforms in France 
(1848-2000), we also compute the variations in realized lifetime well-being for short-lived and long-lived persons associated to those reforms, and we show that those (compensated) uniform working time reductions (and associated rises in real hourly wages) contributed to improve significantly the situation of the shortlived, but at the cost of increasing inequalities.

This paper complements the increasingly large literature on working time regulation and its economic consequences. This paper is not about the effects of those regulations on unemployment and productivity, but, instead, it is about their redistributive consequences in an economy peopled of short-lived and long-lived workers. This paper also complements recent studies on how the government could reduce inequalities in lifetime well-being between short-lived and long-lived persons, as in Fleurbaey and Ponthiere (2013) and Fleurbaey et al (2016). The former paper examines prevention choices, without considering production. The latter paper focuses only on the choice of a retirement age, without considering intensive margins in labor choices. We complement those papers by considering the impacts of different types of working time regulations on inequalities in lifetime well-being between short-lived and long-lived persons.

The paper is organized as follows. Section 2 presents the model. The laissezfaire is characterized in Section 3. Section 4 considers the redistributive impact of (either uncompensated or compensated) uniform working time regulations (with or without overtime work). The ex post egalitarian optimum is characterized in Section 5. Its decentralization is studied in Section 6. Section 7 compares numerically the laissez-faire and the ex post egalitarian optimum. Section 8 explores numerically the impact of working time regulations in France (1848-2000) on the distribution of lifetime well-being. Section 9 concludes.

\section{The model}

We consider a 3-period economy. Each period has a duration normalized to 1. The population is a continuum of agents of size 1 .

Period 1 is childhood. Period 2 is young adulthood, during which individuals work $\ell_{y} \in[0,1]$ units of time, save and consume. Period 3 is old adulthood, during which individuals work $\ell_{o} \in[0,1]$ units of time during a fraction $z$ of that period, and are retired during a fraction $1-z$. Lifetime is risky: only a fraction $\pi \in[0,1]$ of young adults reach the old age.

Individual preferences on lotteries of life satisfy the expected utility hypothesis, and lifetime well-being is supposed to be time-additive. Normalizing the utility of being dead to zero, preferences are represented by the following utility function:

$$
u(c)-v\left(\ell_{y}\right)+\pi\left[u(d)-z v\left(\ell_{o}\right)\right]
$$

where $c$ denotes consumption at young adulthood, $d$ denotes consumption at mature adulthood, and $u(\cdot)$ satisfies $u^{\prime}(\cdot)>0$ and $u^{\prime \prime}(\cdot)<0$. We assume that there exists a consumption level $\bar{c} \geq 0$ such that $u(\bar{c})=0$. The disutility of labor is supposed to be increasing and convex: $v^{\prime}(\cdot)>0$ and $v^{\prime \prime}(\cdot)>0$. We have also $v(0)=0$ and $v^{\prime}(0)=0$. Note that the utility function exhibits no 
pure time preferences. However, the probability to survive to the old age $\pi$ can be interpreted as a biological discount factor.

The labor market is supposed to be perfectly competitive, with an hourly wage equal to $w>0$.

There exists also a perfect annuity market, with actuarially fair return:

$$
\hat{R}=\frac{R}{\pi}
$$

where $R$ equals one plus the interest rate. For the sake of simplicity, we assume that $R=1$.

The first-period budget constraint is:

$$
c+s=w \ell_{y}
$$

where $s$ denotes savings. The second-period budget constraint is:

$$
d=\frac{s}{\pi}+z \ell_{o} w
$$

The intertemporal resource constraint is thus:

$$
c+\pi d=\ell_{y} w+\pi z \ell_{o} w
$$

In the rest of the paper, we also assume there is no public pension system.

\section{Laissez-faire}

As a starting point, let us consider a world without any form of working time regulations, that is, a world where individuals can freely choose how many hours they work at each point in their life (intensive margins of labor) and their retirement age (extensive margins of labor).

At the laissez-faire, individuals choose their consumptions $c$ and $d$, the quantities of hours worked $\ell_{y}$ and $\ell_{o}$, as well as the retirement age $z$, in such a way as to maximize their expected utility subject to their resource constraint:

$$
\begin{aligned}
& \max _{c, d, \ell_{y}, \ell_{o}, z} u(c)-v\left(\ell_{y}\right)+\pi\left[u(d)-z v\left(\ell_{o}\right)\right] \\
& \text { s.t. } \ell_{y} w+\pi z \ell_{o} w \geq c+\pi d
\end{aligned}
$$

Denoting by $\lambda$ the Lagrange multiplier associated to the resource constraint, first order conditions (FOCs) can be rearranged as follows:

$$
\begin{aligned}
& u^{\prime}(c)-\lambda=0 \\
& u^{\prime}(d)-\lambda=0 \\
& w u^{\prime}(c)-v^{\prime}\left(\ell_{y}\right)=0 \\
& w u^{\prime}(d)-v^{\prime}\left(\ell_{o}\right) \geq 0 \\
& w \ell_{o} u^{\prime}(d)-v\left(\ell_{o}\right) \geq 0
\end{aligned}
$$


Consumption is smoothed along the life cycle: $c=d$. The reason lies in the existence of a perfect annuity market with actuarially fair returns, combined with the absence of pure time preferences. The conditions for labor supply is what Jevons (1871) called the "final equivalence of labor and utility". Optimal working time should equalize, at the margin, the utility gain from additional consumption obtained thanks to working more hours (i.e. $\left.w u^{\prime}(c)\right)$ and the utility loss due to the additional disutility from working more hours (i.e. $v^{\prime}\left(\ell_{y}\right)$ ).

Let us now compare (9) and (10). In the Appendix, we show that, given the convexity of $v(\cdot)$, we have $v^{\prime}\left(\ell_{o}\right)>\frac{v\left(\ell_{o}\right)}{\ell_{o}}$, so that, at the equilibrium, the FOC for $\ell_{o}$ is binding but not the FOC for $z$. This implies that the solution for $\ell_{o}$ is interior but that the retirement age $z^{L F}$ is equal to 1 . Moreover, given that consumption is smoothed, we also have that labor is smoothed: $\ell_{y}=\ell_{o}=\ell^{L F}$. Finally, since $w u^{\prime}(c)>v^{\prime}(0)=0$ holds, a necessary and sufficient condition for the existence of a unique and interior level of $\left.\ell^{L F} \in\right] 0,1\left[\right.$ is $w u^{\prime}(w)<v^{\prime}(1)$.

Proposition 1

- If

$$
w u^{\prime}(w)<v^{\prime}(1)
$$

there exists a unique laissez-faire equilibrium with an interior working time at each period.

- At the laissez-faire, the following equalities hold:

$$
\begin{aligned}
u^{\prime}(c) & =u^{\prime}(d) \\
w u^{\prime}(c) & =v^{\prime}\left(\ell_{y}\right) \text { and } w u^{\prime}(d)=v^{\prime}\left(\ell_{o}\right) \\
c+\pi d & =\ell_{y} w+\pi z \ell_{o} w
\end{aligned}
$$

- Those conditions imply:

$$
\begin{aligned}
c^{L F} & =d^{L F}=\ell^{L F} w \\
\ell_{y} & \left.=\ell_{o}=\ell^{L F} \in\right] 0,1[ \\
z^{L F} & =1
\end{aligned}
$$

- We have also:

$$
\begin{aligned}
& \frac{d \ell^{L F}}{d \pi}=\frac{d c^{L F}}{d \pi}=\frac{d z^{L F}}{d \pi}=0 \\
& \frac{d \ell^{L F}}{d w}\left\{\begin{array}{l}
>0 \text { if } R_{c}<1 \\
\leq 0 \text { if } R_{c} \geq 1
\end{array}\right. \\
& \frac{d c^{L F}}{d w}>0 ; \frac{d z^{L F}}{d w}=0
\end{aligned}
$$

where $R_{c}=-\frac{c u^{\prime \prime}(c)}{u^{\prime}(c)}$ is the coefficient of relative risk aversion.

Proof. See the Appendix. 
Thus, at the laissez-faire, individuals perfectly smooth consumption and labor over time (i.e. $c^{L F}=d^{L F}$ and $\ell_{y}=\ell_{o}=\ell^{L F}$ ), and postpone retirement as much as possible (i.e. $z^{L F}=1$ ). As a consequence of late retirement, individuals do not save at all, but consume at each period the product of their labor, that is, $w \ell^{L F}$.

An interesting feature of the laissez-faire is that the consumption and working time profiles are independent from the survival probability $\pi$. This is a direct consequence of assuming a perfect annuity market and from having $z^{L F}=1.4$

Note that Proposition 1 describes not only the laissez-faire equilibrium, but, also the utilitarian social optimum. Actually, a utilitarian social planner maximizing the average realized utility within the population, or, alternatively, the expected utility of a representative agent, would choose consumption and labor profiles that are exactly the same as the ones prevailing at the laissez-faire.

Finally, let us examine the prevalence of inequalities at the laissez-faire. Within our model, all individuals are ex ante identical, and thus make the same decisions concerning consumption and labor profiles. All individuals thus enjoy the same expected lifetime well-being. However, once the durations of life are revealed (i.e. ex post), the population becomes composed of a fraction $\pi$ of longlived individuals, and of a fraction $1-\pi$ of short-lived individuals. Those two groups enjoy different levels of realized lifetime well-being. Short-lived persons have a realized lifetime well-being equal to $u\left(\ell^{L F} w\right)-v\left(\ell^{L F}\right)$, whereas for longlived persons it is equal to $2\left[u\left(\ell^{L F} w\right)-v\left(\ell^{L F}\right)\right]$. Comparing the situations of short-lived and long-lived persons at the laissez-faire, we have that short-lived persons are worse off than long-lived persons if and only if:

$$
U^{L L}-U^{S L}=u\left(\ell^{L F} w\right)-v\left(\ell^{L F}\right)>0
$$

Indeed, in that case, the well-being level associated to the old age is higher than 0 , which is the utility level associated to being dead. Hence long-lived persons enjoy, over their life, a higher lifetime well-being than short-lived persons.

Whether the above inequality is valid or not depends on the level of the wage, and on the functional forms for $u(\cdot)$ and $v(\cdot)$.

Note that a rise in the wage always increases well-being inequalities between short-lived and long-lived persons. Indeed, we have:

$$
u^{\prime}\left(c^{L F}\right) \frac{d c^{L F}}{d w}-v^{\prime}\left(\ell^{L F}\right) \frac{d \ell^{L F}}{d w}=u^{\prime}\left(c^{L F}\right) \ell^{L F}>0
$$

where we made use of the FOC on $\ell$. Therefore, in advanced economies with high productivity (a high $w$ ), it is most likely that $U^{L L}-U^{S L}>0$ is satisfied, and that the long-lived are better off than the short-lived.

\footnotetext{
${ }^{4}$ Indeed, substituting for constant consumption and labor profiles, as well as for $z^{L F}=1$, into the intertemporal budget constraint yields:

$$
c^{L F}(1+\pi)=\ell^{L F} w(1+\pi) .
$$

Thus the life expectancy $1+\pi$ can be simplified from both sides, making the laissez-faire consumption independent from $\pi$. But given the "final equivalence of labor and utility", if consumption is independent from survival conditions, the marginal utility gain from working is also independent from these, implying that the supply of labor is independent from $\pi$.
} 


\section{Uniform working time regulations}

Having characterized the laissez-faire, let us now examine how the introduction of uniform (i.e. age-independent) working time regulations affects individual decisions, as well as the distribution of well-being across long-lived and shortlived individuals.

For that purpose, let us now suppose that the government fixes a uniform maximum working time $\bar{\ell}$ that individuals must respect. Moreover, to focus only on the impact of working time regulations, we assume here that the government imposes mandatory retirement at age $\bar{z}=1$.

When considering uniform working time reductions, several cases can be distinguished. First, the government may either impose a maximum working time $\bar{\ell}$ without any possibility for individuals to work extra hours, or allow for overtime work paid at a higher wage than the actual wage rate. Another important distinction concerns whether the reduction in labor time is associated with a constant hourly wage or not. When the labor time reduction is said to be "uncompensated", the hourly wage remains constant, so that total labor earnings are reduced. On the contrary, when the labor time reduction is "compensated", then the hourly wage is adjusted upwards, so that total labor earnings are left unchanged by the labor time reduction. This section considers the redistributive impact of those distinct types of reforms.

\subsection{No possibility of overtime work}

\subsubsection{Uncompensated reduction of working time}

Let us first consider the simplest reform: an uncompensated labor time reduction without overtime work. When considering the impact of that reform, two cases can arise, depending on whether working time regulations are constraining individual choices or not.

If working time regulations are not constraining, i.e. $\ell_{y}=\ell_{o}=\ell^{L F}<\bar{\ell}$, we obtain the same outcome as at the laissez-faire: $\ell_{y}^{R}=\ell_{o}^{R}=\ell^{L F}$ where $R$ stands for regulation. In that case, consumption is given by $c^{R}=w \ell^{L F}$ and is equal to its laissez-faire level. It is easy to see that, in that case, inequalities between long-lived and short-lived persons remain the same as at the laissez-faire.

If, on the contrary, working time regulations are constraining (i.e. individuals would have chosen $\ell^{L F}>\bar{\ell}$ in the absence of regulation), then individuals now choose, under working time regulations, $\ell_{y}^{R}=\ell_{o}^{R}=\bar{\ell}^{5}$ In that case, consumption is given by:

$$
c^{R}=w \bar{\ell}
$$

\footnotetext{
${ }^{5}$ Note that a solution where $\ell_{y}^{R} \neq \ell_{o}^{R}$ is not possible as at each period, the agent is constrained to work less than he would wish to. In that case, given that he is constrained to work less in the first period (resp. the second) period, he would like to work even more than the laissez faire level in the second (resp. first) period. However, he cannot do so because of working time regulations, $\bar{\ell}$.
} 
which is unambiguously lower than under the laissez-faire, since the working time is lower than in the unconstrained case.

When the regulation constraints individuals, the inequality in realized lifetime well-being between the long-lived and the short-lived is equal to:

$$
U^{L L}-U^{S L}=u(\bar{\ell} w)-v(\bar{\ell})
$$

Hence, when the working time regulation is constraining individuals, inequalities between long-lived and short-lived persons are reduced with respect to the laissez-faire when:

$$
u(\bar{\ell} w)-v(\bar{\ell})<u\left(\ell^{L F} w\right)-v\left(\ell^{L F}\right)
$$

That inequality can be rewritten as:

$$
v\left(\ell^{L F}\right)-v(\bar{\ell})<u\left(\ell^{L F} w\right)-u(\bar{\ell} w)
$$

If the fall in the utility of consumption (RHS) exceeds the fall in the disutility of labor (LHS), then the uniform working time regulation reduces lifetime wellbeing inequalities between the long-lived and the short-lived. However, when the fall in the disutility of labor due to the regulation (LHS) exceeds the welfare loss in terms of consumption (RHS), working time regulations raise inequalities between short-lived and long-lived with respect to the laissez-faire.

Quite interestingly, when the condition for inequality reduction is satisfied, it follows that the realized lifetime well-being level of the short-lived is unambiguously reduced with respect to the laissez-faire. Indeed, when the condition

$$
u(\bar{\ell} w)-v(\bar{\ell})<u\left(\ell^{L F} w\right)-v\left(\ell^{L F}\right)
$$

holds, short-lived persons would have been better off provided they had been left free to choose how much time they could work (without any constraint $\bar{\ell}$ ). Thus, uniform uncompensated labor time reductions can only reduce inequalities in realized lifetime well-being between the long-lived and the short-lived at the cost of making the latter worse off with respect to the laissez-faire. ${ }^{6}$

\subsubsection{Compensated reduction of working time}

Let us now consider the case of compensated labor time reductions, that is, labor time reductions that are carried out without a reduction in total labor earnings. ${ }^{7}$ This amounts to assume that the working time regulation $\bar{\ell}$ is implemented while

\footnotetext{
${ }^{6}$ Note that our results would go through relaxing the assumption that $\bar{z}=1$ and assuming instead that $\bar{z}<1$.

${ }^{7}$ Throughout this paper, we suppose, when there is compensation, that the labor time reduction is fully compensated, that is, that it does not imply any loss in labor earnings. Assuming a full compensation is a simplification; this amounts to assume that there has been a productivity gain allowing workers to earn the same while working less. We thus consider here only two polar cases (fully uncompensated or fully compensated) labor time reductions, whereas other intermediate cases could also be considered.
} 
the hourly wage $w$ is adjusted upwards, so that the total labor income remains unchanged (with respect to the laissez-faire).

Denoting $\ell_{y}^{C R}$ and $\ell_{o}^{C R}$ the labor supply at each period under the regulation, the adjusted hourly wage rates are:

$$
w_{y}^{\prime}=w \frac{\ell^{L F}}{\ell_{y}^{C R}} \text { and } w_{o}^{\prime}=w \frac{L F}{\ell_{o}^{C R}}
$$

Here again, two cases are possible, depending on whether the choice of $\ell^{L F}$ of the laissez-faire is hitting the constraint $\bar{\ell}$. If $\ell^{L F}<\bar{\ell}$, the reform leaves all variables unchanged, and has thus no effect on inequalities between the longlived and the short-lived. ${ }^{8}$

On the contrary, when the regulation constraints individuals $\left(\bar{\ell}<\ell^{L F}\right)$, we have $\ell_{y}^{C R}=\ell_{o}^{C R}=\bar{\ell}$ for the same total income as at the laissez-faire. In that situation, individuals enjoy the same levels of consumption as at the laissez-faire, since income at each period is unchanged (i.e. $\left.w^{\prime}=w \frac{\ell^{L F}}{\bar{\ell}}\right)$ :

$$
c^{C R}=d^{C R}=\bar{\ell} w^{\prime}=\ell^{L F} w
$$

Moreover, since $\ell_{y}^{C R}=\ell_{o}^{C R}<\ell^{L F}$, individuals work fewer hours than at the laissez-faire. Given that individuals enjoy the same consumption but work less, temporal well-being is increased in comparison with the laissez-faire.

As a consequence, a compensated labor time reduction increases the level of well-being of the short-lived. Indeed, since young persons consume the same as at the laissez-faire, but work less, we have:

$$
u\left(c^{C R}\right)-v(\bar{\ell})=u\left(c^{L F}\right)-v(\bar{\ell})>u\left(c^{L F}\right)-v\left(\ell^{L F}\right)
$$

so that the short-lived are here better off than at the laissez-faire.

Note, however, that the above condition implies that the old enjoy not only a higher temporal well-being at the young age, but, also, a higher temporal well-being during their extra period of life, so that there is a rise in inequalities in realized lifetime well-being between the long-lived and the short-lived. Thus the uniform compensated labor time reduction can only make the short-lived better off at the cost of increasing inequalities between the short-lived and the long-lived. Proposition 2 summarizes our results.

Proposition 2 Suppose that the government imposes a maximum number of worked hours $\bar{\ell}$ as well as a mandatory retirement age $\bar{z}=1$. Suppose that the working time regulation constraints individuals.

- Under an uncompensated labor time reduction, we have:

$$
\begin{aligned}
\ell_{y}^{R} & =\ell_{o}^{R}=\bar{\ell}<\ell^{L F} \\
c^{R} & =\bar{\ell} w<c^{L F}
\end{aligned}
$$

\footnotetext{
${ }^{8}$ One crucial assumption here is that labour supply is observable as otherwise, for constant remuneration, the agent would optimally choose a zero labour supply.
} 
An uncompensated labor time reduction reduces inequalities in realized lifetime well-being between the short-lived and the long-lived if and only if:

$$
u(\bar{\ell} w)-v(\bar{\ell})<u\left(\ell^{L F} w\right)-v\left(\ell^{L F}\right)
$$

When that condition holds, the uncompensated labor time reduction makes the short-lived worse off than at the laissez-faire.

- Under a compensated labor time reduction, we have:

$$
\begin{aligned}
\ell_{y}^{C R} & =\ell_{o}^{C R}=\bar{\ell}<\ell^{L F} \\
c^{C R} & =\bar{\ell} w^{\prime}=\ell^{L F} w=c^{L F}
\end{aligned}
$$

A compensated labor time reduction makes the short-lived better off with respect to the laissez-faire, but at the cost of increasing inequalities in realized lifetime well-being between the short-lived and the long-lived, since

$$
u\left(\ell^{L F} w\right)-v(\bar{\ell})>u\left(\ell^{L F} w\right)-v\left(\ell^{L F}\right)
$$

Proof. See above.

Proposition 2 states that uniform labor time reductions leave us with a dilemma. When uncompensated, uniform labor time reductions can decrease inequalities in realized lifetime well-being between the long-lived and the shortlived, but at the cost of making the short-lived worse off than at the laissezfaire. On the contrary, when compensated, uniform labor time reductions make the short-lived better off than at the laissez-faire, but at the cost of further increasing inequalities in realized lifetime well-being between the long-lived and the short-lived in comparison to the laissez-faire.

\subsection{Possibility of overtime work}

Let us now consider another type of working time regulation, where overtime work is possible but at an increased wage. To do so, we assume that below some threshold labor supply $\bar{\ell}$, agents obtain a wage $w$, while beyond this threshold, they obtain a wage $w(1+p)$, where $p$ is strictly positive.

The problem faced by individuals becomes:

$$
\begin{aligned}
& \max _{c, d, \ell_{y}, \ell_{o}} u(c)-v\left(\ell_{y}\right)+\pi\left[u(d)-v\left(\ell_{o}\right)\right] \\
& \text { s.t. } w \bar{\ell}+\left(\ell_{y}-\bar{\ell}\right) w(1+p)+\pi\left(w \bar{\ell}+\left(\ell_{o}-\bar{\ell}\right) w(1+p)\right) \geq c+\pi d \text { if } \ell_{o}, \ell_{y} \geq \bar{\ell} \\
& \text { or } \ell_{y} w+\pi \ell_{o} w \geq c+\pi d \text { if } \ell_{o}, \ell_{y}<\bar{\ell}
\end{aligned}
$$

Under this type of regulation, whether $\ell_{y}^{R R}=\ell_{o}^{R R}$, where ${ }^{R R}$ stands for this second type of working time regulation, is smaller or larger than $\bar{\ell}$ depends on the specific forms of $u(\cdot)$ and $v(\cdot)$ as well as on the size of the premium $p .^{9}$

\footnotetext{
${ }^{9}$ On this, see the numerical illustration in Section 7.
} 
If the solution to this problem is such that $\ell_{o}^{R R}, \ell_{y}^{R R}<\bar{\ell}$, we are back to the laissez-faire solution: $\ell_{o}^{R R}=\ell_{y}^{R R}=\ell^{L F}$. On the contrary, if $\ell_{o}^{R R}, \ell_{y}^{R R} \geq \bar{\ell}$, the FOCs are now:

$$
\begin{aligned}
u^{\prime}(c) & =u^{\prime}(d)=\lambda \\
v^{\prime}\left(\ell_{y}\right) & =v^{\prime}\left(\ell_{o}\right)=w(1+p) \lambda
\end{aligned}
$$

In that situation, we therefore obtain the following solution: $c^{R R}=d^{R R}, \ell_{y}^{R R}=$ $\ell_{o}^{R R}>\ell^{L F}$.

Let us now study how lifetime inequalities are modified by this type of regulation when agents choose to work overtime (i.e. $\ell_{o}^{R R}>\bar{\ell}$ ). ${ }^{10}$ The inequality in realized lifetime well-being is now equal to:

$$
U^{L L}-U^{S L}=u\left(c^{R R}\right)-v\left(\ell_{o}^{R R}\right)
$$

where $\ell_{o}^{R R}>\ell$ and where $c^{R R}$ equals: $c^{R R}=w \bar{\ell}+w(1+p)\left(\ell_{o}^{R R}-\bar{\ell}\right)>w \ell^{L F}$.

Thus, given that inequalities in realized lifetime well-being at the laissez-faire are equal to $u\left(c^{L F}\right)-v\left(\ell^{L F}\right)$, we obtain that a uniform labor time reduction with overtime work reduces inequalities if and only if:

$$
u\left(w \bar{\ell}+w(1+p)\left(\ell_{o}^{R R}-\bar{\ell}\right)\right)-v\left(\ell_{o}^{R R}\right)<u\left(w \ell^{L F}\right)-v\left(\ell^{L F}\right)
$$

Given that old workers work more hours (i.e. $\ell_{o}^{R R}>\ell^{L F}$ ), but also consume more than at the laissez-faire (i.e. $c^{R R}>w \ell^{L F}$ ), it is difficult to know whether a uniform labor time reduction with overtime work increases or decreases inequalities between the long-lived and the short-lived. However, we know for sure that, when that reform allows for a reduction of inequalities, it achieves this at the cost of making the short-lived worse off. Proposition 3 summarizes our results.

Proposition 3 Suppose that the government imposes a maximum number of worked hours $\bar{\ell}$ with the possibility of overtime work at a wage rate $w(1+p)$, as well as a mandatory retirement age $\bar{z}=1$. If agents decide to work overtime,

- We have:

$$
\begin{aligned}
& \ell_{y}^{R R}=\ell_{o}^{R R}>\ell^{L F} \\
& c^{R R}=d^{R R}>c^{L F}
\end{aligned}
$$

- A uniform labor time reduction with the possibility of overtime work reduces inequalities in realized lifetime well-being between the short-lived and the long-lived (with respect to the laissez-faire) if and only if:

$$
u\left(w \bar{\ell}+w(1+p)\left(\ell_{o}^{R R}-\bar{\ell}\right)\right)-v\left(\ell_{o}^{R R}\right)<u\left(w \ell^{L F}\right)-v\left(\ell^{L F}\right)
$$

When that condition holds, the labor time reduction with the possibility of overtime work makes the short-lived worse-off than at the laissez-faire.

\footnotetext{
${ }^{10}$ Obviously, if the solution is the laissez-faire, inequalities remain identical.
} 
Proof. See above.

Thus, the possibility of overtime work does not change the dilemma faced: when the uniform labor time reduction can achieve a reduction in inequalities in realized lifetime well-being, this is at the cost of making the unlucky short-lived worse off than at the laissez-faire. This somewhat negative result motivates us to go beyond uniform working time regulations, in order to consider agespecific working time regulations (Section 6). But before considering these, it is important to first characterize what the social optimum looks like in the present context. For that purpose, Section 5 characterizes the ex post egalitarian optimum.

\section{The ex post egalitarian optimum}

Inequalities in realized lifetime well-being between the short-lived and the longlived can be questioned from an ethical perspective. Actually, in our model, all individuals are perfectly identical ex ante, that is, before the duration of life is revealed. No one can do anything to influence his or her survival chances. Longevity inequalities are thus arbitrary, and can be regarded as circumstances, on which individuals have no influence. Hence, if one adheres to the Principle of Compensation (Fleurbaey and Maniquet, 2004, Fleurbaey 2008), according to which inequalities due to circumstances should be abolished, it follows that the government should intervene to reduce inequalities in realized lifetime well-being due to unequal exogenous lifetimes.

But in order to do justice to the idea of compensating the short-lived, one cannot, in the present context, rely on a utilitarian social welfare function, since we show above that this social criterion would, in the present context, legitimate the laissez-faire, and the resulting inequalities in realized lifetime well-being between short-lived and long-lived persons.

In the following, we propose to do justice to the compensation of the shortlived by considering an ex post egalitarian social welfare function, which takes as objective the maximization of the realized lifetime well-being of the worst off in the society (see Fleurbaey et al 2014).

When considering the compensation of the short-lived, an important difficulty consists of the impossibility, for the government, to identify ex ante (i.e. before the duration of each life is known) individuals who will turn out to be short-lived. Indeed, governments have access to large statistical information on factors affecting survival, but have no information at the individual level, which is the level relevant for compensation.

Under an ex post egalitarian social objective, and taking into account the impossibility to identify the short-lived ex ante, the social planner's problem can be written as:

$$
\begin{aligned}
\max _{c, d, \ell_{y}, \ell_{o}, z} \min & \left\{u(c)-v\left(\ell_{y}\right), u(c)-v\left(\ell_{y}\right)+u(d)-z v\left(\ell_{o}\right)\right\} \\
\text { s.t. } & \ell_{y} w+\pi z \ell_{o} w \geq c+\pi d
\end{aligned}
$$


Note that, because of the identification constraint, the realized lifetime wellbeing of the short-lived, i.e. $u(c)-v\left(\ell_{y}\right)$, must be exactly identical to the realized well-being of the long-lived when being young, i.e. $u(c)-v\left(\ell_{y}\right)$.

The above objective function is not differentiable. But we can rewrite that problem as the maximization of first-period utility subject to the constraint that the long-lived is not worse off than the short-lived. The problem becomes:

$$
\begin{array}{ll}
\max _{c, d, \ell_{y}, \ell_{o}, z} & u(c)-v\left(\ell_{y}\right) \\
& \text { s.t. } \ell_{y} w+\pi z \ell_{o} w \geq c+\pi d \\
& \text { s.t. } u(d)-z v\left(\ell_{o}\right) \geq 0
\end{array}
$$

Denoting the optimal level of variables with *, and denoting by $\lambda$ the Lagrange multiplier associated to the resource constraint, and by $\mu$ the Lagrange multiplier associated to the egalitarian constraint, FOCs yield:

$$
\begin{aligned}
& u^{\prime}\left(c^{*}\right)=\lambda \\
& u^{\prime}\left(d^{*}\right)=\frac{\pi}{\mu} \lambda \\
& v^{\prime}\left(\ell_{y}^{*}\right)=\lambda w \\
& \lambda \pi w-v^{\prime}\left(\ell_{o}^{*}\right) \mu \geq 0 \\
& \lambda \pi w \ell_{0}-v\left(\ell_{0}\right) \mu \geq 0
\end{aligned}
$$

as well as the conditions:

$$
\begin{aligned}
& \lambda \geq 0, \ell_{y}^{*} w+\pi z^{*} \ell_{o}^{*} w \geq c^{*}+\pi d^{*} \\
& \mu \geq 0, u\left(d^{*}\right)-z^{*} v\left(\ell_{o}^{*}\right) \geq 0
\end{aligned}
$$

with complementary slackness.

Those conditions can be rewritten as follows:

$$
\begin{aligned}
& u^{\prime}\left(c^{*}\right)=\frac{\mu}{\pi} u^{\prime}\left(d^{*}\right) \\
& v^{\prime}\left(\ell_{y}^{*}\right)=u^{\prime}\left(c^{*}\right) w \\
& u^{\prime}\left(d^{*}\right) w-v^{\prime}\left(\ell_{o}^{*}\right) \geq 0 \\
& u^{\prime}\left(d^{*}\right) w-\frac{v\left(\ell_{o}^{*}\right)}{\ell_{o}^{*}} \geq 0
\end{aligned}
$$

Given the convexity of $v(\cdot)$, it is clear, as before, that the FOCs for $\ell_{o}^{*}$ and $z^{*}$ cannot be both binding. As a solution to this system, we will therefore have that $\ell_{0}^{*}$ satisfies $u^{\prime}\left(d^{*}\right) w=v^{\prime}\left(\ell_{o}^{*}\right)$ and $z^{*}=1$. Our analysis of those conditions yields the following results, which are summarized in Proposition 4. 


\section{Proposition 4}

- At the ex post egalitarian optimum, we have:

$$
\begin{aligned}
u^{\prime}\left(c^{*}\right) & =\frac{\mu}{\pi} u^{\prime}\left(d^{*}\right) \\
v^{\prime}\left(\ell_{y}^{*}\right) & =u^{\prime}\left(c^{*}\right) w \\
v^{\prime}\left(\ell_{o}^{*}\right) & =u^{\prime}\left(d^{*}\right) w \\
\ell_{y}^{*} w+\pi z^{*} \ell_{o}^{*} w & =c^{*}+\pi d^{*} \\
u\left(d^{*}\right) & =z^{*} v\left(\ell_{o}^{*}\right) \\
z^{*} & =1
\end{aligned}
$$

- Those conditions imply

- if $\frac{\mu}{\pi} \leq 1$,

$$
\begin{aligned}
& c^{*} \geq d^{*}>\bar{c} \\
& \ell_{o}^{*} \geq \ell_{y}^{*} \text { and } z^{*}=1
\end{aligned}
$$

- if $\frac{\mu}{\pi}>1$,

$$
\begin{aligned}
d^{*} & >c^{*} \text { and } c^{*}, d^{*}<\bar{c} \\
\ell_{o}^{*} & <\ell_{y}^{*} \text { and } z^{*}=1
\end{aligned}
$$

Proof. It directly follows from FOCs (16)-(19).

The ex post egalitarian optimum does not, in general, involve flat consumption profiles and flat labor profiles. The social optimum thus differs quite a lot from the laissez-faire (and the utilitarian social optimum). When the shadow price of relaxing the egalitarian constraint is lower than the survival probability to the old age (i.e. the chance that these inequalities are effectively realized), the egalitarian optimum involves a decreasing consumption profile with the age, as well as an increasing labor profile with the age. Hence, according to that social criterion, older, more experienced workers should work more. The underlying intuition is that forcing older workers to work more hours implies that more resources can be transferred to the young age, and, hence, to individuals who may turn out to be short-lived. On the contrary, when the shadow price of relaxing the egalitarian constraint is high, the egalitarian optimum involves a consumption profile increasing with the age and decreasing labor supply. That second case is quite extreme: it corresponds to a situation of extreme misery where resources are so scarce that living longer decreases lifetime utility.

Focussing on the first, more plausible case, we obtain that the ex post egalitarian optimum involves a decreasing consumption profile, and an increasing labor profile. The intuition behind that result goes as follows. Given that shortlived persons only enjoy the young age, the social planner can only make the short-lived better off by transferring consumption and leisure towards the young age, while reducing old-age consumption and leisure. By doing so, the realized lifetime well-being of the short-lived is increased. Note that the social planner does not know, ex ante, who will be short-lived or long-lived, but imposing 
decreasing consumption profiles and increasing labor profiles for all suffices to improve the situation of individuals who will turn out to be short-lived.

Note also that, by construction, we have, at the ex post egalitarian optimum, a full equalization of the realized lifetime well-being of short-lived and long-lived individuals, since, by the egalitarian constraint, we have:

$$
u\left(d^{*}\right)=v\left(\ell_{o}^{*}\right)
$$

Thus, although the fraction $\pi$ of the population enjoys a longer lifetime than the fraction $1-\pi$, this does not prevent equality in realized lifetime well-being. Actually, old-age consumption is fixed to a level such that the utility of oldage consumption is exactly equal to the disutility of old-age labor, so that the surviving old are indifferent between dying prematurely and surviving. The realized lifetime well-being levels associated to a long life and a short life are, by construction of consumption and labor profiles, exactly equal in the two cases. This equalization is achieved despite the non-identification ex ante of the premature dead persons. Thus, the ex post egalitarian optimum allows both to maximize the realized lifetime well-being of the short-lived, and to minimize inequalities in realized lifetime well-being.

\section{Age-specific regulation and decentralization}

Let us now examine how the ex post egalitarian optimum could be decentralized by an appropriate working time regulation. For that purpose, we consider here the impact of introducing age-specific working time regulations, which, unlike in Section 4, consists of constraints on working time that differ along the life cycle. The underlying intuition for introducing age-specific working time regulations is that, at the ex post egalitarian optimum, we have, in general, an increasing labor profile with the age (i.e. $\left.\ell_{y}^{*}<\ell_{o}^{*}\right) .{ }^{11}$ Hence it makes sense to examine to what extent imposing such age-specific labor standards can reduce inequalities between the long-lived and the short-lived, and make the short-lived better off in comparison to the laissez-faire.

\subsection{Uncompensated age-specific working time regulation}

In order to study the impact of age-specific working time regulation, let us first consider a government that imposes individuals to work a maximal number of hours $\ell_{y}^{*}$ at the young age and $\ell_{o}^{*}$ at the old age. The levels $\ell_{y}^{*}$ and $\ell_{o}^{*}$ are the quantities of labor that prevail at the ex post egalitarian optimum under $\mu<\pi$, so that we have $\ell_{y}^{*}<\ell_{o}^{*}$. The government also imposes mandatory retirement at age $z^{*}=1$, also in line with the ex post egalitarian optimum.

At the laissez-faire, individuals choose the ex post egalitarian retirement age. Therefore, only three cases can arise: either the constraints on labor supply are not binding at any age, or they are binding only at the young age, or they are binding both at the young age and at the old age.

\footnotetext{
${ }^{11}$ Throughout this section, we focus on the general case where $\frac{\mu}{\pi} \leq 1$.
} 
Let us first consider the case where the laissez-faire labor supply is lower than the constraint imposed by working time regulation, i.e. $\ell^{L F} \leq \ell_{y}^{*}<\ell_{o}^{*}$. In that situation, consumption levels are the same as at the laissez-faire: $c^{R}=$ $d^{R}=\ell^{L F} w$ and the regulation has no impact at all.

If, on the contrary, working time regulations are constraining in both periods, i.e. $\ell_{y}^{*}<\ell_{o}^{*} \leq \ell^{L F}$, the labor supply chosen by the agent hits the constraint, so that $\ell_{y}^{R}=\ell_{y}^{*}$ and $\ell_{o}^{R}=\ell_{o}^{*}$. Individuals still choose to retire at $z^{*}=1 .^{12}$ Consumptions are still smoothed, and are now smaller than at the laissez-faire:

$$
c^{R}=d^{R}=\frac{\ell_{y}^{*} w+\pi \ell_{o}^{*} w}{1+\pi}<w \ell^{L F}
$$

If working time regulations are constraining only at the young age but not at the old age, i.e. if $\ell_{y}^{*}<\ell^{L F}<\ell_{o}^{*}$, the labor supply under the regulation is $\ell_{y}^{R}=\ell_{y}^{*}$ and $\ell^{L F}<\ell_{o}^{R} \leq \ell_{o}^{*}$. Interestingly, the labor supply at the old age under regulation constraints is likely to be higher than its laissez-faire level, since the agent is constrained in the first period to supply less labor than he would have wished to work at the laissez-faire. This reduces consumption possibilities, which raises the marginal utility of consumption, and, hence, pushes individuals to work more at the old age, as the individual trade-off between consumption and labor $w u^{\prime}\left(c^{R}\right)=v^{\prime}\left(\ell_{0}^{R}\right)$ shows. In that situation, consumptions are given by:

$$
c^{R}=d^{R}=\frac{\ell_{y}^{*} w+\pi \ell_{o}^{R} w}{1+\pi} \lessgtr w \ell^{L F}
$$

since $\ell_{y}^{R}=\ell_{y}^{*}<\ell^{L F}$ and $\ell_{o}^{R}>\ell^{L F} .{ }^{13}$

Age-specific working time regulations do not, on their own, suffice to decentralize the ex post egalitarian optimum. There are two reasons why they cannot achieve that decentralization. First, in all these three cases, consumption is smoothed along the life-cycle, contrary to the ex post egalitarian optimum, which involves a decreasing consumption profile. Second, working time regulations enable to obtain the ex post egalitarian labor supply levels only when working hours both at young and old ages are larger at the laissez faire than at the ex post egalitarian optimum.

Let us now consider how age-specific labor time regulations affect inequalities in realized lifetime well-being between the long-lived and the short-lived. Obviously, in the case where working time regulations are not constraining, well-being inequalities remain the same as at the laissez-faire.

When working time regulations are constraining at both periods, inequalities in realized lifetime well-being are now:

$$
U^{L L}-U^{S L}=u\left(\frac{\ell_{y}^{*} w+\pi \ell_{o}^{*} w}{1+\pi}\right)-v\left(\ell_{o}^{*}\right)
$$

\footnotetext{
${ }^{12}$ Indeed, individuals are here forced to supply less labor than they would wish to, so that they would like to retire even later than at the laissez-faire, which is not possible given the mandatory retirement at $\bar{z}=1$.

${ }^{13}$ Note that $z^{R}=1$ since we still have $v\left(\ell_{o}^{R}\right) / \ell_{o}^{R}>v^{\prime}\left(\ell_{o}^{R}\right)=w u^{\prime}\left(c^{R}\right)$.
} 
while theses inequalities at the laissez-faire are $u\left(w \ell^{L F}\right)-v\left(\ell^{L F}\right)$ with $c^{R}=$ $\frac{\ell_{y}^{*} w+\pi \ell_{o}^{*} w}{1+\pi}<w \ell^{L F}$ and $\ell_{o}^{*}<\ell^{L F}$. Hence, depending on the specific forms of $u(\cdot)$ and $v(\cdot)$, working time regulations may either decrease or increase lifetime well-being inequalities between short-lived and long-lived agents.

Unlike under uniform uncompensated labor time reductions, it is not necessarily the case that a reduction in inequalities is achieved at the cost of making the short-lived worse off. To see this, note that, when:

$$
u\left(\frac{\ell_{y}^{*} w+\pi \ell_{o}^{*} w}{1+\pi}\right)-v\left(\ell_{o}^{*}\right)<u\left(w \ell^{L F}\right)-v\left(\ell^{L F}\right)<u\left(\frac{\ell_{y}^{*} w+\pi \ell_{o}^{*} w}{1+\pi}\right)-v\left(\ell_{y}^{*}\right)
$$

inequalities in realized lifetime well-being are reduced with respect to the laissezfaire, whereas the realized lifetime well-being of the short-lived is higher than at the laissez-faire. Thus imposing age-specific uncompensated working time regulations can, in some cases, allow us to escape from the dilemma between reducing inequalities and making the short-lived better off.

Finally, in the case where working time regulations are constraining in the first period but not in the second, inequalities between short-lived and long-lived individuals are reduced with respect to the laissez-faire when:

$$
u\left(\frac{\ell_{y}^{*} w+\pi \ell_{o}^{R} w}{1+\pi}\right)-v\left(\ell_{o}^{R}\right)<u\left(w \ell^{L F}\right)-v\left(\ell^{L F}\right)
$$

where $\ell_{y}^{*}<\ell^{L F}<\ell_{o}^{R}$. The second term is smaller on the LHS than on the RHS, which goes in the direction of reducing inequalities in lifetime well-being between the short-lived and the long-lived. However, the combination of a rise in the working time of the old and a fall of the working time of the young has ambiguous effects on consumption (first term), so that it is not necessarily the case that working time regulations can reduce inequalities.

Note that, here again, it is possible that the age-specific working time regulation achieves both a reduction of inequalities and an improvement of the situation of the short-lived. This double goal is achieved when:

$$
u\left(\frac{\ell_{y}^{*} w+\pi \ell_{o}^{R} w}{1+\pi}\right)-v\left(\ell_{o}^{R}\right)<u\left(w \ell^{L F}\right)-v\left(\ell^{L F}\right)<u\left(\frac{\ell_{y}^{*} w+\pi \ell_{o}^{R} w}{1+\pi}\right)-v\left(\ell_{y}^{*}\right)
$$

Thus, contrary to what prevails under uniform uncompensated labor time regulations, age-specific uncompensated labor time regulations can, in some cases, both reduce inequalities and make the short-lived better off.

\subsection{Compensated age-specific working time regulation}

Let us now consider compensated age-specific labor time regulation, that is, agespecific working time regulations $\ell_{y}^{*}$ and $\ell_{o}^{*}$ with $\ell_{y}^{*}<\ell_{o}^{*}$ that are implemented while maintaining the total labor earnings constant (i.e. equal to their laissezfaire levels, $w \ell_{y}$ and $w \ell_{o}$ ). 
Denoting $\ell_{y}^{C R}$ and $\ell_{o}^{C R}$, the labor supply chosen at each period in response to the regulation, this implies that the wage rate increases if working time decreases such that $w_{y}^{\prime}=w \frac{\ell^{L F}}{\ell_{y}^{C R}}$ and $w_{o}^{\prime}=w \frac{\ell^{L F}}{\ell_{o}^{C R}}$. For simplicity, we set $\bar{z}=1$. Three cases can arise.

If $\ell^{L F}<\ell_{y}^{*}<\ell_{o}^{*}$, the regulation is inefficient, $\ell_{y}^{C R}=\ell_{o}^{C R}=\ell^{L F}$ and we obtain the same results as in the laissez-faire.

If, on the contrary, $\ell_{y}^{*}<\ell_{o}^{*}<\ell^{L F}$, the individual is constrained to work less than he would wish to in both periods: $\ell_{y}^{C R}=\ell_{y}^{*}$ and $\ell_{o}^{C R}=\ell_{o}^{*}$. In that situation, inequalities in realized lifetime well-being between the long-lived and the short-lived unambiguously increase with respect to the laissez-faire, since

$$
u\left(w \ell^{L F}\right)-v\left(\ell^{L F}\right)<u\left(w_{o}^{\prime} \ell_{o}^{*}\right)-v\left(\ell_{o}^{*}\right)
$$

At the old age, workers work less than at the laissez-faire, and enjoy the same consumption as at the laissez-faire (since $\left.w_{o}^{\prime} \ell_{o}^{*}=w \ell^{L F}\right)$. Hence, the wellbeing of the extra period lived is higher than at the laissez-faire, which raises inequalities between the long-lived and the short-lived.

In that case, the short-lived is better off than at the laissez-faire, since:

$$
u\left(w \ell^{L F}\right)-v\left(\ell^{L F}\right)<u\left(w_{y}^{\prime} \ell_{y}^{*}\right)-v\left(\ell_{y}^{*}\right)
$$

Total labor earnings is unchanged $\left(w_{y}^{\prime} \ell_{y}^{*}=w \ell^{L F}\right)$, while fewer hours are worked than at the laissez-faire (i.e. $\ell_{y}^{*}<\ell^{L F}$ ).

If $\ell_{y}^{*}<\ell^{L F}<\ell_{o}^{*}$, the regulation is constraining in the first period but not in the second one, so that $\ell_{y}^{C R}=\ell_{y}^{*}$ and $\ell^{L F} \leq \ell_{o}^{C R} \leq \ell_{o}^{*}$. Hence inequalities remain identical or decrease with respect to the laissez faire, since $w_{o}^{\prime} \ell_{o}^{C R}=w \ell^{L F}$ and $\ell^{L F} \leq \ell_{O}^{C R}$

$$
u\left(w \ell^{L F}\right)-v\left(\ell^{L F}\right) \geq u\left(w_{o}^{\prime} \ell_{o}^{C R}\right)-v\left(\ell_{o}^{C R}\right)
$$

It is reasonable to assume that $\ell_{o}^{C R}$ remains equal to $\ell^{L F}$, since there is no marginal benefit for an old individual to increase his labor supply (it would not change his remuneration under this type of regulation), so that inequalities between long-lived and short-lived individuals remain the same as at the laissezfaire.

Here again, the short-lived is better off than at the laissez-faire, since:

$$
u\left(w \ell^{L F}\right)-v\left(\ell^{L F}\right)<u\left(w_{y}^{\prime} \ell_{y}^{*}\right)-v\left(\ell_{y}^{*}\right)
$$

In the light of all this, it appears that age-specific working time regulations can have various effects, depending on whether these are compensated or not, and on whether these are constraining at both ages of life or only at the young age. Proposition 5 summarizes our results.

Proposition 5 Suppose that the government imposes age-specific working time regulations $\ell_{y}^{*}$ and $\ell_{o}^{*}$ with $\ell_{y}^{*}<\ell_{o}^{*}$ as well as a mandatory retirement age $\bar{z}=1$. Focusing on the cases where the regulation constraints individuals at least in one period of life, we have: 
- Under an uncompensated age-specific labor time regulation:

- when the regulation constraints individuals in both periods, it can both reduce inequalities and make the short-lived better off when:

$$
u\left(\frac{\ell_{y}^{*} w+\pi \ell_{o}^{*} w}{1+\pi}\right)-v\left(\ell_{o}^{*}\right)<u\left(w \ell^{L F}\right)-v\left(\ell^{L F}\right)<u\left(\frac{\ell_{y}^{*} w+\pi \ell_{o}^{*} w}{1+\pi}\right)-v\left(\ell_{y}^{*}\right)
$$

- when the regulation only constraints individuals at the young age, it can both reduce inequalities and make the short-lived better off when:

$$
u\left(\frac{\ell_{y}^{*} w+\pi \ell_{o}^{R} w}{1+\pi}\right)-v\left(\ell_{o}^{R}\right)<u\left(w \ell^{L F}\right)-v\left(\ell^{L F}\right)<u\left(\frac{\ell_{y}^{*} w+\pi \ell_{o}^{R} w}{1+\pi}\right)-v\left(\ell_{y}^{*}\right)
$$

- Under a compensated age-specific labor time regulation,

- when the regulation constraints individuals in both periods, it makes the short-lived better off, but at the cost of increasing inequalities with respect to the laissez-faire.

- when the regulation only constraints individuals at the young age, it makes the short-lived better off, and it leaves inequalities unchanged.

Proof. See above.

Although fixing the maximum working time at each age to the socially optimal levels does not allow to decentralize the ex post egalitarian optimum, imposing age-specific working time regulations can, in some cases, both reduce inequalities in realized lifetime well-being between the short-lived and the longlived and make the short-lived better off. Achieving this double goal was impossible with uniform labor time regulations, which could only reduce inequalities at the cost of making the short-lived worse off than at the laissez-faire. Thus, in a second-best world with a limited number of available policy instruments, imposing age-specific - rather than uniform - labor time regulations can be regarded as a way to achieve, under some conditions, both a reduction of inequalities and an improvement of the situation of the unlucky short-lived.

\subsection{Decentralization of the ex post egalitarian optimum}

Let us now study the tax-schedule that would allow to fully decentralize the ex post egalitarian optimum. Comparing the conditions in Proposition 1 with those in Proposition 4, it is clear that one needs a tax on the return of savings $\tau$ so as to induce the optimal decreasing consumption pattern, as well as lump sum transfers so as to satisfy the egalitarian constraint.

Under such a tax on savings, the FOC for savings obtained from the individual's problem becomes:

$$
u^{\prime}(c)=(1-\tau) u^{\prime}(d)
$$


while the socially optimal profile satisfies:

$$
u^{\prime}\left(c^{*}\right)=\frac{\mu}{\pi} u^{\prime}\left(d^{*}\right)
$$

Hence one needs to set the tax on savings returns equal to:

$$
\tau^{*}=1-\frac{\mu}{\pi}=1-\frac{u^{\prime}\left(c^{*}\right)}{u^{\prime}\left(d^{*}\right)}
$$

Hence, if $\mu<\pi$, agents face a tax on savings. By taxing the return on savings, the government induces agents to have the optimal consumption profile, and reduces consumption at the old age with respect to the laissez-faire.

One also needs to impose lump sum transfers $T=d^{*}-d^{L F}$ so as to ensure that the egalitarian constraint, $u\left(d^{*}\right)=z^{*} v\left(\ell_{o}^{*}\right)$ where $z^{*}=1$ is satisfied at the decentralized optimum. Proposition 6 summarizes our results.

Proposition 6 The ex post egalitarian optimum can be decentralized by means of a tax on savings returns equal to:

$$
\tau^{*}=1-\frac{\mu}{\pi}=1-\frac{u^{\prime}\left(c^{*}\right)}{v^{\prime}\left(\ell_{o}^{*}\right)} w
$$

as well as lump sum transfers

$$
T=d^{*}-d
$$

so as to satisfy the egalitarian constraint.

Proof. See above.

If the goal of the government is to decentralize the ex post egalitarian optimum (at which the well-being of the worst off is maximized and inequalities are minimized), the best instruments are a tax on savings return and a lump sum tax, rather than working time regulations. As shown by the tax formula, the tax on savings returns should be positive, so as to induce the optimal decreasing consumption profiles and increasing working time profiles.

The decentralization of the ex post egalitarian social optimum does not require any working time regulation: by taxing savings, the government will, on the basis of Jevons's (1871) final equivalence of labor and utility, increase the marginal utility gain from consumption at the old age, which will induce old agents to work more, in line with the social optimum.

\section{Numerical illustration}

Whereas the previous sections delivered analytical results, one may be curious to put numbers into the model, to see to what extent the ex post egalitarian optimum differs from the laissez-faire, and to examine also the impact of various working time regulations on the distribution of lifetime well-being. 
Throughout this section, we will assume that annual utility of consumption and annual disutility of work are represented by the functions:

$$
u(c)=T_{1} \frac{c^{1-\frac{1}{\gamma}}}{1-\frac{1}{\gamma}}+\alpha \text { and } v(\ell)=T_{2} \beta \frac{\ell^{2}}{2}+\theta
$$

where $T_{1}$ (resp. $T_{2}$ ) is the total number of weeks in a year (resp. of weeks worked in a year). Throughout this section, we set $T_{1}=52$ and $T_{2}=47$, in order to conform to what prevails in France (i.e. 5 weeks of paid holidays).

Regarding the calibration of preference parameters $\alpha, \beta, \gamma$ and $\theta$, a major difficulty lies in the fact that the laissez-faire is not observable, since in contemporary economies the working time is subject to regulations. Thus we can hardly take the observed working time as resulting from a free optimization problem of the agent. Hence, to construct the hypothetical laissez-faire, we will consider two distinct combinations of preference parameters, one under which individuals would, at the laissez-faire, work more than under the current regulations, and one under which they would work less than under the current regulations. Those two hypothetical laissez-faire equilibria differ on the value of the parameter $\beta$ (disutility of labor). We fix $\beta=6$ in the first case and $\beta=12$ in the second one. Regarding other preference parameters, we assume, following Becker et al. (2005), that $\gamma=1.250$ and $\alpha=-16.2$. We also set $\theta=0$.

Assuming that agents devote 8 hours a day to basic daily life activities, this leaves 16 hours as a maximum quantity of work per day. We set the working time regulation to $\bar{\ell}=35 / 80=0.4375$ where 35 hours is the working time limit per week in many countries (for example, in France) and $16 \times 5=80$ would be the maximum possible length of working time per week.

We assume that the childhood period lasts 20 years and that the periods of young adulthood and old adulthood last 30 years each, so that the maximal longevity is 80 years. Assuming, like in many countries, that the legal retirement age is 65 years, this yields that $\bar{z}=(65-50) /(80-50)=0.5$. Moreover, given that life expectancy is equal to $50+30 \pi$ in our model, we set $\pi=0.9$, which yields a life expectancy of 77 years (close to OECD average). Finally, the hourly wage is set to $w=\$ 10$, while extra worked hours are paid with a premium $p$ equal to, respectively, 20 and $50 \%{ }^{14}$

Tables 1 reports the variables of interest under the laissez-faire (LF), under uniform uncompensated working time regulation (UUR), uniform compensated working time regulation (UCR) and under the uniform working time regulation with overtime work (UROT), under the case where $\beta$ is small (so that agents at the LF would work more than the legal norm) and the case where $\beta$ is high (so that agents would work less at the LF than the legal norm). ${ }^{15}$

\footnotetext{
${ }^{14}$ Focusing on France, Cahuc and Carcillo (2014) show that the increase in remuneration after the legal time limit of 35 hours a week varies with the size and sector of firms, as well as with the number of hours above the legal limit. In general, $p$ ranges between $10 \%$ and $50 \%$.

${ }^{15}$ In any case, when the government regulates the working time duration, it also constrains the retirement age to $\bar{z}$.
} 


\begin{tabular}{|c|c|c|c|c|c|c|c|c|c|c|}
\hline & \multicolumn{5}{|c|}{$\begin{array}{l}\text { low disutility of labor } \\
\qquad(\beta=6)\end{array}$} & \multicolumn{5}{|c|}{$\begin{array}{l}\text { high disutility of labor } \\
\qquad(\beta=12)\end{array}$} \\
\hline & $\mathrm{LF}$ & UUR & UCR & $\begin{array}{c}\text { UROT } \\
p=0.2\end{array}$ & $\begin{array}{c}\text { UROT } \\
p=0.5\end{array}$ & $\mathrm{LF}$ & UUR & UCR & $\begin{array}{c}\text { UROT } \\
p=0.2\end{array}$ & $\begin{array}{l}\text { UROT } \\
p=0.5\end{array}$ \\
\hline$c$ & 404 & 267 & 404 & 397 & 475 & 275 & 210 & 275 & 237 & 303 \\
\hline$d$ & 404 & 267 & 404 & 397 & 475 & 275 & 210 & 275 & 237 & 303 \\
\hline$\ell_{y}(\mathrm{~h} /$ week $)$ & 40 & 35 & 35 & 49 & 53 & 27 & 27 & 27 & 31 & 38 \\
\hline$\ell_{0}(\mathrm{~h} /$ week $)$ & 40 & 35 & 35 & 49 & 53 & 27 & 27 & 27 & 31 & 38 \\
\hline$z$ (years) & 80 & 65 & 65 & 65 & 65 & 80 & 65 & 65 & 65 & 65 \\
\hline$U^{S L}$ & 307 & 288 & 316 & 289 & 293 & 283 & 282 & 283 & 264 & 286 \\
\hline$U^{L L}-U^{S L}$ & 307 & 301 & 330 & 315 & 324 & 283 & 245 & 300 & 286 & 291 \\
\hline
\end{tabular}

Table 1: The laissez-faire and various uniform working time regulations.

For any level of labor disutility, imposing a uniform uncompensated working time regulation (UUR) reduces inequalities, but at the cost of making the shortlived worse-off than at the laissez-faire. ${ }^{16}$

Turning now to uniform compensated labor reduction (UCR), we can see that imposing such a reform makes the short-lived better off under low disutility of labor (because the young enjoy the same consumption as at the laissez-faire, while working less), and does not affect his well-being under high disutility of labor (since at the laissez-faire the young already work less than $\bar{\ell}$ ). However, in both cases, inequalities are larger than at the laissez-faire. ${ }^{17}$

Regarding the possibility of overtime work at an extra wage, we can see that, in any case, overtime work increases inequalities with respect to the laissezfaire. ${ }^{18}$ Moreover, when the disutility of labor is low, the possibility of overtime work makes the short-lived worse off, and can, under a high disutility of labor, make him better off only if the extra wage is large enough.

Let us now turn to the comparison between the laissez-faire (LF), the ex post egalitarian social optimum (EO) and the age-specific uncompensated and compensated working time regulations (resp. AUR and ACR). Table 2 presents the results of our numerical simulations, under our two cases (i.e. low and high disutility of labor). ${ }^{19}$

\footnotetext{
${ }^{16}$ When labour disutility is high, only the retirement age (and thus consumption) is reduced compared to the laissez faire as $\ell_{L F}<\bar{\ell}$.

${ }^{17}$ This effect is reinforced by the decrease in the legal retirement age. When the agent works less than the maximum working time regulation, welfare inequalities also increase simply because the retirement age decreases (which is different from our theoretical part where it was assumed that the retirement age stayed the same and thus inequalities were left unchanged).

${ }^{18}$ Note that, under the regulation, agents cannot choose the laissez-faire solution anymore (even though they may be better-off in terms of lifetime welfare), since by law, they are obliged to retire at $\bar{z}$, as well as to be remunerated at $w(1+p)$ for every worked hours above $\bar{\ell}$.

${ }^{19}$ When we assume $\beta=6$, we need to constrain $\ell_{o}^{*}=1$ (i.e. agents cannot work more than 80 hours a week). When $\beta=12$, it is always the case that $\ell_{o}^{*} \leq 1$.
} 


\begin{tabular}{l|cccc|cccc}
\hline \hline & \multicolumn{3}{|c|}{ low disutility of labor } & \multicolumn{3}{c}{ high disutility of labor } \\
& \multicolumn{3}{|c}{$\beta=6)$} & \multicolumn{4}{c}{$(\beta=12)$} \\
& LF & EO & AUR & ACR & LF & EO & AUR & ACR \\
\hline \hline$c$ & 404 & 923 & 333 & 404 & 275 & 724 & 221 & 275 \\
$d$ & 404 & 6 & 333 & 404 & 275 & 79 & 221 & 275 \\
$\ell_{y}$ (h/week) & 40 & 21 & 21 & 21 & 27 & 13 & 13 & 13 \\
$\ell_{0}$ (h/week) & 40 & 80 & 47 & 40 & 27 & 74 & 33 & 27 \\
$z$ (years) & 80 & 80 & 80 & 80 & 80 & 80 & 80 & 80 \\
$U^{S L}$ & 307 & 398 & 320 & 333 & 283 & 381 & 295 & 310 \\
$U^{L L}-U^{S L}$ & 307 & 0 & 281 & 307 & 283 & 0 & 255 & 283 \\
\hline \hline
\end{tabular}

Table 2: Laissez-faire and ex post egalitarian optimum.

The ex post egalitarian optimum involves a strongly decreasing consumption profile with the age, and a strongly increasing labor profile with the age, which enables to both increase the well-being of the short-lived and to cancel out well-being inequalities. The optimal number of hours worked is about 20 hours per week for young adults, which is quite close to the 4 hours a day proposed by Campanella (1602) in The City of the Sun. However, for old workers, the optimal number of hours worked is about four times larger. The intuition behind that differentiated treatment of young and old workers is that, contrary to Campanella (1602), where working time regulations are seen as a way to avoid the alienation of humans, working time regulations are used here to compensate the short-lived. Note that the lower the disutility of labor is (i.e. the lower $\beta$ is), and the lower is the ratio old working time / young working time. ${ }^{20}$

When the government only fixes working standards at the young and the old age (without compensation), the constraint is binding only at the young age ( since $\ell_{y}^{*}<\ell^{L F}<\ell_{o}^{*}$ ), so that the agent re-optimizes and chooses consumption and labor supply at the old age taking into account that he would like to supply more labor at the young age than what he constrained to. Compared to the laissez-faire, inequalities between short-lived and long-lived agents decrease, while the well-being of the short-lived increases. ${ }^{21}$ Under the compensated regulation framework, the well-being of the short-lived also increases with respect to the laissez-faire, and well-being inequalities remain identical. ${ }^{22}$

\section{Working time reforms in France (1848-2000)}

Let us conclude our investigations by going back to history, and to the working time regulation reforms introduced during the last two centuries. How did those reforms affect the distribution of realized lifetime well-being? Did those reforms reduce inequalities between the long-lived and the short-lived?

\footnotetext{
${ }^{20}$ The ratio is about 4 when $\beta=6$, against 5 when $\beta=12$.

${ }^{21} \mathrm{We}$ tried with other values for $\beta$ in the range $[4,20]$. These results were confirmed.

${ }^{22}$ This is due to the fact that second-period consumption is the same as at the laissez faire, so that the agent chooses to supply the laissez-faire labor in the second period (since higher quantities of labor would have no impact on his earnings).
} 
In order to answer those questions, this section calibrates our model, taking into account the variations in policy parameters $T_{2}$ (number of working weeks in a year), $\bar{\ell}$ (working time limit in a week) and $\bar{z}$ (legal retirement age) over the last two centuries in France. ${ }^{23}$ The calibration is shown on Table $3{ }^{24}$

\begin{tabular}{ccccc}
\hline \hline Year & $T_{2}$ & & worked hours per week & retirement age \\
1848 & 52 & $84 \Longrightarrow \bar{\ell}=84 / 126=0.666$ & NA $\Longrightarrow \bar{z}=1$ \\
1900 & 52 & $70 \Longrightarrow \bar{\ell}=70 / 126=0.555$ & NA $\Longrightarrow \bar{z}=1$ \\
1919 & 52 & $48 \Longrightarrow \bar{\ell}=48 / 126=0.380$ & $65 \Longrightarrow \bar{z}=0.500$ \\
1936 & 50 & $40 \Longrightarrow \bar{\ell}=40 / 126=0.317$ & $65 \Longrightarrow \bar{z}=0.500$ \\
1982 & 47 & $39 \Longrightarrow \bar{\ell}=39 / 126=0.309$ & $60 \Longrightarrow \bar{z}=0.330$ \\
2000 & 47 & $35 \Longrightarrow \bar{\ell}=35 / 126=0.277$ & $60 \Longrightarrow \bar{z}=0.330$
\end{tabular}

Table 3: Working time reforms in France and calibration of labor parameters.

Over the period considered, there have been substantial variations in all macroeconomic aggregates, including the real wage rate. In order to take those variations into account, we use the recent work by Zwart et al. (2014), who provide estimates, over the last two centuries, of the daily real wage of a building laborer. Each figure on the second column of Table 4 corresponds to the real wages of building laborers defined as "the number of subsistence baskets that a daily wage buys". ${ }^{25}$ The last column reports the full-week-worked-equivalent hourly wage. The hourly wage is computed as if agents were working the total number of hours over 7 days (and not over 5 days as today). ${ }^{26}$

\begin{tabular}{cccc}
\hline \hline Year & daily wage & \# worked hours a week & Hourly wage $w$ \\
1848 & 14 & 84 & $14 /(84 / 7)=1.67$ \\
1900 & 29 & 70 & $29 /(70 / 7)=2.9$ \\
1919 & 13 & 48 & $13 /(48 / 7)=1.90$ \\
1936 & 15 & 40 & $15 /(40 / 7)=2.625$ \\
1982 & $37.9^{*}$ & 39 & $37.9 /(39 / 7)=6.80$ \\
2000 & $93.5^{*}$ & 35 & $93.5 /(35 / 7)=18.7$ \\
\hline \hline
\end{tabular}

Table 4: Daily real wages (source: de Zwart et al. (2014)), and hourly wages, France, 1848-2000.

Table 4 shows that, over the period considered, the real wage has grown strongly. This rise in the real wage has several causes, whose study goes beyond

\footnotetext{
${ }^{23}$ To compute values $\bar{\ell}$, we assume that agents can work at most 126 hours a week. This is equivalent to 18 hours devoted to work everyday (while 6 hours remain for daily living). The value for $\bar{\ell}$ is thus obtained by normalizing the number of hours worked in a week over the maximum length of working time.

${ }^{24}$ Before 1919, there is no legal retirement age so that we assume that agents are working the full old-adulthood period.

${ }^{25}$ French real wages are not available for 1982 and 2000 . The figures in Table 4 with a * are obtained by linear interpolation assuming a trend similar to the one in Western Europe.

${ }^{26}$ For example, in 1848, the daily wage is 14 baskets for 12 hours of work a day (over 7 days a week), which gives a hourly wage of $14 /(84 / 7)=1.67$ basket, while in 1982 , the daily wage is 37.9 baskets for 39 hours a week (over 5 days), so that the full-week-worked-equivalent hourly wage is $93.5 /(39 / 7)=18.7$ baskets.
} 
the scope of this paper. Note, however, that some part of the rise in the real wage may be due to working time reforms. Indeed, working time reforms involved a reduction in the number of worked hours, while maintaining the total labor income unchanged (which implies mechanically a rise in the hourly wage).

Finally, the survival rate $\pi$ was calibrated as shown in Table $5 .{ }^{27}$

\begin{tabular}{ccc}
\hline \hline years & life expectancy at age 10 & $\pi$ \\
1848 & 47.13 & 0.240 \\
1900 & 50.40 & 0.350 \\
1919 & 51.76 & 0.390 \\
1936 & 57.71 & 0.590 \\
1982 & 69.77 & 0.992 \\
2000 & 73.24 & $0.999^{*}$ \\
\hline
\end{tabular}

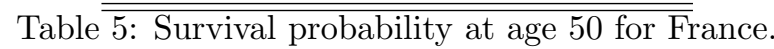
(source Human Mortality database)

Since the unit of the real wage is a subsistence basket, we can calibrate the intercept of the temporal utility function $\alpha$ in such a way that an individual with a consumption equal to one subsistence basket (i.e. 7 subsistence baskets per week) would be indifferent between life and death. Thus we compute the value for $\alpha$ as the solution to $u(7)-v\left(\bar{\ell}_{1848}\right)=0$, that is, to:

$$
52 \frac{7^{1-\frac{1}{\gamma}}}{1-\frac{1}{\gamma}}+\alpha-T_{2,1848} \beta \frac{\left(\bar{\ell}_{1848}\right)^{2}}{2}=0
$$

It yields a value of $\alpha=-314.37$ for $\beta=6$ and $\gamma=1.25$.

Using the parametrization described above for $\left(\pi, w, \bar{z}, \bar{\ell}, T_{2}, \alpha, \beta, \gamma\right)$, Table 6 reports the realized lifetime well-being levels for the short-lived and the longlived, as well as inequalities in lifetime well-being between them, for 1848-2000. ${ }^{28}$

\begin{tabular}{cccccccc}
\hline \hline years & $u(c)$ & $\bar{z} v(\ell)$ & $U_{S L}$ & $U_{L L}$ & $U_{L L}-U_{S L}$ & $\Delta U_{S L}(\%)$ & $\Delta U_{L L}(\%)$ \\
1848 & 384.46 & 69.33 & 315.13 & 630.26 & 315.13 & - & - \\
1900 & 438.07 & 48.15 & 389.93 & 779.85 & 389.93 & $+23.7 \%$ & $+23.7 \%$ \\
1919 & 307.71 & 11.32 & 285.07 & 581.46 & 296.39 & $-26.8 \%$ & $-25.4 \%$ \\
1936 & 318.61 & 7.56 & 303.49 & 614.54 & 311.05 & $+6.4 \%$ & $+5.6 \%$ \\
1982 & 417.86 & 4.50 & 404.35 & 817.70 & 413.35 & $+33.2 \%$ & $+33.0 \%$ \\
2000 & 562.55 & 3.63 & 551.67 & 1110.59 & 558.92 & $+36.4 \%$ & $+35.8 \%$ \\
\hline
\end{tabular}

Table 6: Realized lifetime well-being for short/long lived, 1848-2000.

${ }^{27}$ The above values for $\pi$ are obtained as follows:

$$
10+\text { life expectancy at } 10=50+30 \pi .
$$

We use values for life expectancy at age 10, since infant mortality was high in 1848 and 1900 . The value marked with ${ }^{*}$ was constrained to 0.999 .

${ }^{28}$ We have: $U_{S L}=u(c)-v(\bar{\ell}) ; U_{L L}=2 u(c)-(1+\bar{z}) v(\bar{\ell})$, where $c=d=\frac{w \bar{\ell}(1+\pi \bar{z})}{1+\pi}$. Note that when $\bar{z}=1$ as in 1848 and $1900, c=d=w \bar{\ell}$, while if $\bar{z}<1, c=d<w \bar{\ell}$. 
Uniform working time regulations have, in association with the rise in the real wage, contributed to increase the realized lifetime well-being of the worst off, i.e. the short-lived (except for 1919). ${ }^{29}$ However, those reforms implied also larger inequalities between the short-lived and the long-lived..$^{30}$

In sum, the evaluation of the effects of past working time regulations on the distribution of well-being in the population is complex. Assuming an invariant lifetime utility function over a period as long as 150 years is a strong assumption. Moreover, many dimensions of standards of living have changed over that period (i.e. rises in the real wage and in life expectancy), and one cannot attribute the entire welfare gains to working time regulations. Having stressed those limitations, our calculations suggest nonetheless that, along with uniform working time regulations, the distribution of realized lifetime well-being within the population has evolved substantially. Inequalities went up, but at the same time the situation of the worst off (the unlucky short-lived) has considerably improved. Thus, although we remain far from the ex post egalitarian optimum, there has been a significant improvement of the situation of the worst-off.

\section{Conclusion}

This paper examined, from a lifecycle perspective, the redistributive effects of working time regulations in an economy where individuals have unequal longevity. For that purpose, we first studied the impact of labor supply decisions on inequalities in realized lifetime well-being between the long-lived and the short-lived in the absence of any government intervention. Then, we explored the impact of imposing uniform working time reductions (compensated/uncompensated, with/without overtime work) on those inequalities.

Imposing uniform labor time reductions lead us to a kind of dilemma. When the uniform labor time reduction is uncompensated (i.e. the hourly wage being constant), this can reduce inequalities in realized lifetime well-being with respect to the laissez-faire, but at the cost of making the short-lived worse off. On the contrary, compensated labor time reductions (i.e. total labor earnings being constant) make the short-lived better off than at the laissez-faire, but at the cost of increasing inequalities between the long-lived and the short-lived.

In a second stage, we contrasted the laissez-faire with the ex post egalitarian social optimum, and we showed that, under the latter, the consumption profile is generally decreasing with the age, whereas the working hours profile is increasing with the age, unlike at the laissez-faire. Our numerical calculations suggest that the ex post egalitarian optimum involves about 20 hours worked per week at the young age. Those numbers are not far from the 4 hours a day proposed by Campanella (1602). But for older adults, the working time would be about 4

\footnotetext{
${ }^{29}$ It is assumed here that the working time regulation constraints (at the extensive and the intensive margins) are binding (agents never supply less labour than the regulation).

${ }^{30}$ The origin of this rise in well-being inequalities depends on the joint evolution of the wage, the labor time and the retirement age. For instance, between 1848 and 1900, both $w$ and $\pi$ have increased while $\bar{\ell}$ decreased, which resulted in an increase in consumption and a decrease in disutility of work. Both these effects increase inequalities in lifetime well-being.
} 
times larger. The reason is that working time regulation is not used here as an instrument against workers' alienation (as it is in Campanella), but as a way to guarantee some justice between the short-lived and the long-lived.

We also showed that the ex post egalitarian optimum cannot be decentralized by working time restrictions, even when these are age-specific. Indeed, although such restrictions can, under some conditions, reduce the size of inequalities, these regulations do not allow for decentralizing the decreasing consumption profile with the age. Hence, these do not suffice to abolish inequalities in lifetime well-being between the short-lived and the long-lived.

Finally, we complemented those analytical findings by some numerical explorations showing that uniform working time regulations in France (1848-2000) have, over the last two centuries, been associated with a rise in inequalities in realized lifetime well-being between short-lived and long-lived individuals, but also with an improvement of the situation of the worst off (the short-lived).

All in all, this paper finds some support for the use of age-specific working time regulations as a kind of second-best redistributive device (from lucky long-lived individuals towards unlucky short-lived individuals) in a world where the taxation of savings return and lump sum taxation are subject to strong political constraints. In a first-best world (without such restrictions), a tax on savings and lump sum transfers would suffice to decentralize the ex post egalitarian optimum. However, once those instruments are unavailable (or limited by exogenous constraints), age-specific working time regulations can, under some conditions, help making the short-lived better off while reducing inequalities.

\section{References}

Askenazy, P. (2013). Working time regulation in France from 1996 to 2012. Cambridge Journal of Economics, 37 (2): 323-347.

Becker, G., Philipson, T., Soares, R. (2005). The quantity and the quality of life and the evolution of world inequality. American Economic Review, 95 (1), 277-291.

Cahuc P., Carcillo, S. (2014). The detaxation of overtime hours: lessons from the French experiment. Journal of Labor Economics, 32(2), 361-400.

Campanella, T. (1602). Civitas Solis [The City of the Sun], Italian version.

Chemin, M., Wasmer, E. (2009). Using Alsace-Moselle local laws to build a difference-indifferences estimation strategy of the employment effects of the 35-hour workweek regulation in France, Journal of Labor Economics, 27 (4): 487-524.

Christensen, K., Johnson, T., Vaupel, J. (2006). The quest for genetic determinants of human longevity: challenges and insights. Nature Review Genetics, 7, 436-448.

Crépon, B., Kramarz, F. (2002). Employed 40 hours or not-employed 39: lessons from the 1982 mandatory reduction of the workweek, Journal of Political Economy, 110 (6): 1355-1389.

Crépon B., Leclair, M., Roux, S. (2004). RTT, productivité et emploi: nouvelles estimations sur données d'entreprises, Économie et Statistique, 376 (7): 55-89.

de Zwart, Pim, Bas van Leeuwen and Jieli van Leeuwen-Li (2014), "Real wages since 1820", in Jan Luiten van Zanden, et al. (eds.), How Was Life?: Global Well-being since 1820, OECD Publishing. http://dx.doi.org/10.1787/9789264214262-8-en 
Fleurbaey, M. (2008). Fairness, responsibility and welfare. Oxford University Press.

Fleurbaey, M., Leroux, M.L., Ponthiere, G. (2014). Compensating the dead. Journal of Mathematical Economics, 51 (C): 28-41.

Fleurbaey, M., Leroux, M.L., Pestieau, P., Ponthiere, G. (2014). Fair retirement under risky lifetime. International Economic Review, 57 (1): 177-210.

Fleurbaey, M., Maniquet, F. (2004). Compensation and responsibility. In: K. J. Arrow \& A. K. Sen \& K. Suzumura (ed.), Handbook of Social Choice and Welfare, edition 1, volume 2, chapter 22: 507-604.

Fleurbaey, M., Ponthiere, G. (2013). Prevention against equality? Journal of Public Economics, 103 (C): 68-84.

Friesen, J. (2000). Overtime pay regulation and weekly hours of work in Canada, Labour Economics, 8, 691-720

Goux, D., Maurin, E., Petrongolo, B. (2011). Worktime Regulations and Spousal Labour Supply, IZA Discussion Paper 5639.

Holmlund, B. and Pencavel, J. (1988). The determination of wages, employment and work-hours in an economy with centralised wage-setting: Sweden, 1950-83, Economic Journal, 98, 1105-1126.

Human Mortality Database. University of California, Berkeley (USA), and Max Planck Institute for Demographic Research (Germany). Available at www.mortality.org.

Hunt, J. (1999). Has work-sharing worked in Germany? Quarterly Journal of Economics, 114: 117-48

Jevons, W.S. (1871). The theory of political economy, Penguin Classics, London.

More, T. (1516). Utopia. London.

\section{Appendix}

\subsection{Proof of Proposition 1}

Imposing the condition:

$$
w u^{\prime}(w)<v^{\prime}(1)
$$

guarantees that, when there is a flat labor profile with no savings and with late retirement $(z=1)$, this is achieved for a level of labor that is strictly inferior to 1. Note also that the condition:

$$
w u^{\prime}(0)>v^{\prime}(0)=0
$$

trivially holds. That condition guarantees that, when there is a flat labor profile with no savings and with late retirement $(z=1)$, this is achieved for a level of labor that is strictly superior to 0 .

Given those two conditions, we know that, when the labor profile is flat and there is no savings and late retirement, there exists a unique interior level of labor $\left.\ell^{L F} \in\right] 0,1[$ that satisfies the FOCs.

Let us now show why it is optimal for individuals to have a flat labor profile with no savings and with late retirement $\left(z^{L F}=1\right)$. Rearranging the FOCs for 
old age labor and for retirement, we obtain:

$$
\begin{aligned}
& F O C_{\ell}=w u^{\prime}(d)-v^{\prime}\left(\ell_{o}\right) \geq 0 \\
& F O C_{z}=w u^{\prime}(d)-\frac{v\left(\ell_{o}\right)}{\ell_{o}} \geq 0
\end{aligned}
$$

Given that $v(\cdot)$ is convex, it is necessarily the case that: $v^{\prime}\left(\ell_{o}\right)>\frac{v\left(\ell_{o}\right)}{\ell_{o}}$. This implies that in equilibrium, $z^{L F}=1$ and $\ell^{L F} \in[0,1]$. We can show this by contradiction. Assume $z<1$ so that $F O C_{z}=0$. Under the convexity of $v($.$) ,$ this implies that $F O C_{\ell}<0$ which is not consistent with $F O C_{\ell}$. Alternatively, assume $F O C_{\ell}=0$ for $\ell_{0}>0$; this implies that $F O C_{z}>0$ consistent with $z=1$.

From the intertemporal budget constraint, and substituting for $c=d, z=1$ and $\ell_{y}=\ell_{o}=\ell$, we obtain:

$$
c(1+\pi)=\ell w+\pi \ell w \Longleftrightarrow c^{L F}=\ell^{L F} w \text { and } s^{L F}=0
$$

Given that the conditions $w u^{\prime}(w)<v^{\prime}(1)$ and $w u^{\prime}(0)>v^{\prime}(0)=0$ are satisfied, we know that when there is a flat labor profile with no savings and with late retirement $\left(z^{L F}=1\right)$, this is achieved for a unique interior level of labor $\left.\ell^{L F} \in\right] 0,1[$. We thus obtain the interiority of the optimal quantities of labor at the laissez-faire.

We can also use the previous conditions to do some comparative statics. Suppose, for instance, that the survival probability goes up. We have:

$$
w u^{\prime}(\ell w)-v^{\prime}(\ell)=0
$$

so that

$$
\begin{aligned}
& \frac{d \ell^{L F}}{d \pi}=0 \\
& \frac{d c^{L F}}{d \pi}=0 \\
& \frac{d z^{L F}}{d \pi}=0 .
\end{aligned}
$$

Consider now a change in the wage rate $w$. We have:

$$
\frac{d \ell^{L F}}{d w}=-\frac{\frac{d\left(w u^{\prime}(\ell w)-v^{\prime}(\ell)\right)}{d w}}{w^{2} u^{\prime \prime}(\ell w)-v^{\prime \prime}(\ell)}=-\frac{u^{\prime}(\ell w)+u^{\prime \prime}(\ell w) w \ell}{w^{2} u^{\prime \prime}(\ell w)-v^{\prime \prime}(\ell)} \gtrless 0
$$

The denominator is negative, but the sign of the numerator is ambiguous and depends on whether the coefficient of relative risk aversion $R_{c}=-c u^{\prime \prime}(c) / u^{\prime}(c)$ is greater or smaller than 1 . If $R_{c}<1, d \ell^{L F} / d w>0$ while if $R_{c} \geq 1, d \ell^{L F} / d w \leq 0$. From the budget constraint, $c^{L F}=w \ell^{L F}$, we have that $d c^{L F} / d w=\ell^{L \bar{F}}+$ $w d \ell^{L F} / d w$ so that together with the expression for $d \ell^{L F} / d w$, we obtain that $d c^{L F} / d w>0$ always.

Obviously, $d z^{L F} / d w=0$. 